\section{Psychiatry, hegemony and the myth of mental illness}

Dear Editor, The recent paper by Kelly et al entitled The Myth of Mental IIIness: 50 years after publication: What does it mean today? published in the Ir J Psych Med 2010; 27(1): 35-43 made fascinating reading. The discussion involved a timely examination of the contribution of Szasz's seminal work, ${ }^{1}$ and follows a pattern that may be seen in other work, such as Lupton's revisitation of Illich's work Medical Nemesis. ${ }^{2}$

The authors are to be commended for including a response from Szasz himself and the perspective of a former (involuntary) patient with mental health issues, as well as commentaries by psychiatrists, and associated lecturers. One cannot help but feel however that a more robust examination of Szasz's contribution might have been gleaned if the consultation process had cast a wider net. It might for example have benefitted from the perspectives of nursing or clinical psychology. It would undoubtedly have benefitted from commentaries from those from a social work, social care or sociology of health perspective. Recent textbooks for example on sociology and health continue to acknowledge the key role played by Szasz in exposing issues of power and the social construction of mental health and illness. ${ }^{3}$

Szasz's work ultimately focuses on power and conformity. Anti-oppressive practice and values must form the bedrock of the day to day work of those from a social work and social care background. Social work in particular is a highly politicised discipline in many countries and this article fails to acknowledge their stance on Szasz's work.

I was initially both horrified and annoyed to read the commentary by Niall Crumlish, specialist registrar in psychiatry, when, in answer to the question 'What does The Myth of Mental Illness mean today?' he responded 'The short answer: not a lot'. However, upon reflection, I feel that this appraisal is in part both right and wrong. It is wrong in the sense that, to a small degree, the power imbalance between psychiatrists and patients has altered, albeit marginally. Evidence for this may be seen in the growing voice and profile of organisations representing people with mental health issues, and perhaps more importantly in the Mental Health Act (2001) which legislated for crucial safeguards for patients (the Mental Health Tribunals). Without the whole scale assault on the hegemony of psychiatry initiated by seminal works such as The Myth of Mental IIIness it is highly unlikely that such crucial changes would ever have occurred.

However, there is undoubtedly some truth in Crumlish's blunt statement 'not a lot'. Szasz's work has not had the impact in Ireland that one might have expected or hoped. The power base of medicine and psychiatry remains far stronger here in Ireland, than say in our nearest neighbour, the UK. Ireland remains a more conservative and hierarchical country, despite been recently thrust towards what has been described as 'high modernity'.

Medicine and psychiatry are in part to blame for this power imbalance, but some blame must also be attributed to the other disciplines within the multidisciplinary team. Neither clinical psychology nor social work, ${ }^{5}$ or any of the other disciplines seem willing or able to robustly challenge the dominance of psychiatry. Compared with many other countries these groups appear remarkably unpoliticised, more akin to handmaidens to medicine/psychiatry, than the natural foils to counter the power of medicine which is within their potential.

Health and social care professionals (as well as other sectors of society) need to be able to identify and acknowledge unequal power relations, hierarchies, exclusion and the social construction of 'reality'. It is essential that practitioners and students are able to reflect on normative, social constructionist and radical views of widely believed and accepted 'facts'. This would include being able to explore diagnosis from multiple perspectives including: diagnosis as fact; diagnosis as script; and diagnosis as ideology.

The evaluation of the impact of Szasz's work as underwhelming in Ireland is not surprising. It represents a sad indictment on the near absolute dominance of psychiatry and the timidity of other mental health related disciplines. What this evaluation starkly reveals is that Szasz's critique is probably more important and relevant in Ireland, even after 50 years, than most of us would like to acknowledge.

Frank Houghton,

Irish Centre for Research on Applied Social Studies (ICRASS), Limerick Institute of Technology, Limerick, Ireland.

References

1. Szasz TS. The myth of mental illness. The American Psychologist 1960; 15: 113-118.

2. Lupton D. Limits to medicine. Medical nemesis. J Health Serv Res Policy 2005; 10(2): 122-123

3. Morrall P. Sociology and Health. London: Routledge, 2009

4. Peillon M. Community of distrust. In: Peillon M, Slater E (Eds). Encounters with modern Ireland. Dublin: Institute of Public Administration, 1998

5. Butler S. Mental Health Social Work in Ireland: Missed Opportunities? In Keane $N(E d)$. Social Work in Ireland: historical perspectives. Dublin: Institute of Public Administration, 2005 